\title{
QUANDO AS OVELHAS PASTAM NO ORIENTE: \\ ESPAÇOS INTERSEMIÓTICOS ENTRE CAIO \\ FERNANDO ABREU \\ E O I CHING: O LIVRO DAS MUTAÇÕES
}

\section{Anselmo Peres Alós*}

RESUMO: A proposta do presente estudo é a de desenvolver uma leitura intersemiótica da obra Ovelhas Negras, do escritor gaúcho Caio Fernando Abreu (1995), fazendo emergir da superfície textual seu hipotexto oriental. Se a linguagem poética sempre é ao menos dupla, interagindo com o corpus de textos a ela contemporâneos ou antecessores, em Caio Fernando Abreu o diálogo que estabelece a ambivalência semiótica de seus contos remonta ao I Ching, obra clássica chinesa que se configura como expoente de duas importantes correntes filosóficas orientais: o taoísmo e o confuncionismo.

PALAVRAS-CHAVE: Conto Sul-riograndense, Filosofia Oriental, Intertextualidade

RÉSUMÉ: L'avant-propos de cet étude est la élaboration d'une lecture intersémiotique de l'oeuvre Ovelhas Negras, écrite par Caio Fernando Abreu (1995). L'intention de cet lecture est met en relief, dans la surface textuel, son hypotexte oriental. Si le langage poétique se configure toujours comme un double qui dialogue avec un corpus de textes antérieurs ou contemporaines d'elle, dans l'oeuvre de Caio Fernando Abreu on peut affirmer que le dialogue établi par les textes de cet livre de contes remonte au I-Ching, une oeuvre classique de la philosophie chinoise, qui est l'expoent de deux importantes tendences philosophiques de l'Orient: le taoísme et le confuncionisme.

MOTS-CLÉ: Conte Sul-riograndense, Philosophie Orientale, Intertextualité. 
*Doutorando pela Universidade Federal do Rio Grande do Sul UFRGS

As palavras só contam o que se sabe. Mas quem disser: Deus é um espirito de paz, Está repetindo um menino de sete anos, que acrescentou: Eu tenho medo é de dia; de noite não, Porque é claro. (ADÉLIA PRADO, 2001, p. 39)

\section{INTRODUÇÃO}

Ovelhas Negras, livro de contos publicado por Caio Fernando Abreu em 1995, reúne 24 textos escritos entre 1962 e 1995. O título do livro fala por si mesmo: trata-se de uma coletânea de manuscritos produzidos durante 33 anos de vida literária. A respeito da obra, afirma o autor à orelha do livro: "[n]ão consigo senti-lo (...) como reles fundo-de-gaveta, mas sim como uma espécie de autobiografia ficcional, uma seleta de textos que acabaram ficando fora de livros individuais".

O que se pode apreender deste comentário é que Ovelhas Negras se configura como a obra marginal par excellence de Caio Fernando Abreu. Destarte, faz-se necessário pensar até que ponto essa "marginalidade" não é intencional, se mantivermos em mente que Abreu não apenas escreveu sobre sexo, drogas e rock'n roll, mas também carregou os estigmas da homossexualidade e da contaminação pelo vírus da AIDS. Talvez justamente por ser o mais "maldito" de seus livros, Ovelhas Negras seja a chave de leitura para sua obra (pensada enquanto um todo orgânico), ocupando assim esse livro o mesmo lugar privilegiado que Uma Aprendizagem on O Livro dos Prazeres ocupa na obra de Clarice Lispector (aliás, influência confessa de Abreu ${ }^{1}$, deveras citada em epígrafes, mencionada constantemente pelos narradores criados pelo autor e mesmo pelos personagens).

Ovelhas Negras traz um arranjo estrutural arrojado e intrigante: os contos estão divididos em três grandes blocos, contendo cada bloco oito contos. Cada um destes blocos encontra-se sob o signo 
de um hexagrama oriundo do I Ching, o Livro das Mutações. Ainda que o I Ching seja considerado o mais antigo dos oráculos chineses, faz-se necessário ressaltar que, muito mais do que um oráculo, o Livro das Mutações é uma importante fonte de duas grandes correntes do pensamento chinês: o taoísmo e o confuncionismo.

Ainda no âmbito estrutural do livro, cada conto traz um pequeno prefácio, ou "o conto do conto", como os chamou Abreu na orelha de seu livro:

[Esses contos] foram às vezes publicados em antologias, revistas, jornais, edições alternativas. Mas grande parte é de inéditos relegados a empoeiradas pastas dispersas por várias cidades, e que só agora - como pastor eficiente que me pretendo - consegui reunir. Cada conto tem seu "conto do conto", freqüentemente mais maluco que o próprio, e essas histórias também entram em forma de mini-prefácios. A ordem é quase cronológica, mas não rigorosa: alguns tinham a mesma alma, embora de tempos diversos, e foram agrupados na mesma, digamos, enfermaria.

Mais do que dar informações sobre a gênese de cada conto, esses pequenos prefácios remetem à própria estrutura do I Ching. Composto por 64 hexagramas, corresponde a cada hexagrama um texto fragmentário, segmentado em quatro partes distintas: $O$ Julgamento (texto acrescido a cada um dos hexagramas pelo Rei Wen), As Linhas Mutáveis (incorporadas pelo Duque de Chou) e $A$ Imagem e $O$ Comentário, (incluídos por Confúcio). Os prefácios de Abreu funcionam de forma análoga aos comentários de Confúcio em cada hexagrama.

Se a influência de Clarice Lispector é um dado afirmado e reiterado pelo próprio autor, como pode ser averiguado no prefácio à segunda edição de Inventário do Ir-Remediável, o mesmo pode ser dito da influência do I Ching em sua obra. Caio Fernando Abreu foi um escritor profundamente interessado em estudos esotéricos, particularmente na Astrologia, no Tarot e no I Ching. Ao explorar 
tais referências presentes em sua obra, a intenção que se quer mostrar não é a de tornar Abreu uma espécie de "profeta místico" ou "personalidade iluminada"; ao contrário, o que se pretende é, a partir da explicitação desses elementos tornar possível uma leitura de sentidos aparentemente herméticos, presentes na obra de Abreu e ainda não completamente explorados ${ }^{2}$. Assim, este trabalho tem como meta, pois, investigar como se dão as relações intertextuais entre as três primeiras narrativas do livro e o I Ching, dado que a primeira parte do livro está colocada sob o signo de Ch'ien, O Criativo.

Para operacionalizar as relações estabelecidas entre os textos, utilizar-me-ei da categoria intertextualidade, forjada por Julia Kristeva em Sèméiotikè: recherches pour une sémanalyse (1969). Kristeva parte de Bakhtin para desenvolver a noção de intertextualidade. Se o lingüista russo defende que a constituição de todo o enunciado lingüístico se dá a partir de relações dialógicas entre o texto literário e o texto histórico-social, Kristeva por sua vez avança a partir destas reflexões, operacionalizando esse raciocínio a partir de uma visada semiótica, formulando a já mencionada categoria:

(...) tout texte se constituit comme mosaïque des citations, tout texte est absortion et transformation d'un autre texte. À la place de la notion d'intersubjectivité s'intalle celle d'intertextualité, et le language poétique se lit, au moins, comme double (1969, p. 146).

Logo, a intertextualidade fica sendo definida como a interação semiótica de um texto com outro texto. Intertexto, por sua vez, é o texto ou o corpus de textos com os quais um determinado texto mantém aquele tipo de interação. Michael Riffaterre (1978) propõe que seja estabelecido - para definir a intertextualidade - que se leve em consideração uma relação estabelecida através de qualquer tipo de identidade estrutural (como se texto e intertexto se configurassem como variantes de uma mesma estrutura). Aguiar e Silva discorda dessa postura de Riffaterre, lembrando que tal afirmação está ligada a uma "metafísica estruturalista” (SILVA, 1993, p. 626) que falseia 
- ao mesmo tempo em que não compreende - a dinâmica semiótica em toda a sua abrangência. $\mathrm{O}$ intertexto, por sua existência anterior e subterrânea ao texto, pode ser lido "debaixo" - por assim dizer - da superfície do texto. Assim, há um texto outro, palimpséstico, oculto sob o texto, o que justifica a utilização de termos como subtexto e hipotexto no lugar da consagrada categoria intertextualidade (RIFATERRE, 1978 e 1979).

\section{REALIZANDO A PRIMEIRA LEITURA}

É sob o signo do Criativo que Caio Fernando Abreu organiza a primeira seqüência de narrativas. Neste primeiro bloco de contos, oito textos estão subordinados à seguinte epígrafe: "aparece uma revoada de dragões sem cabeça”. Esta frase corresponde às Linhas Mutáveis do primeiro hexagrama do I Ching. A revoada de dragões sem cabeça ocorre quando todas as linhas do hexagrama são mutáveis. Sendo Ch'ien composto unicamente por linhas yang, a mutação das seis linhas conduz ao segundo hexagrama (K'un, o Receptivo), composto de linhas ying. Ch'ien e K'un são hexagramas que correspondem à cristalização das essências yang e ying, respectivamente. Ying e yang são paradigmas complementares e não excludentes na cultura chinesa, ao contrário dos binarismos da cultura ocidental. É importante manter em mente que é a complementaridade e a permanente alternância entre o ying e o yang, e não
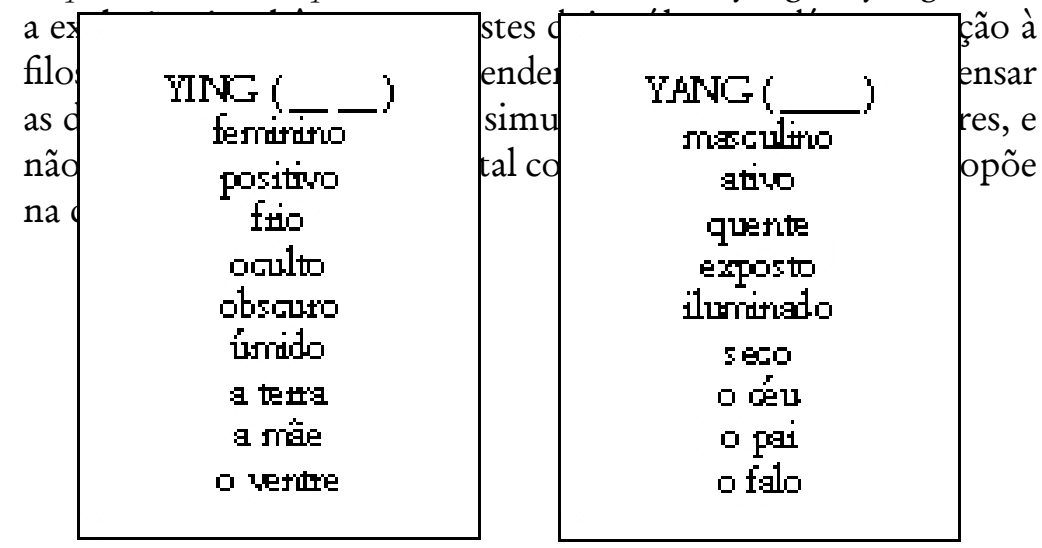
Assim, ao utilizar os aspectos ligados à coincidência das seis linhas mutáveis em Ch'ien (identificável pela frase e, tal ocorrência correspondente), transformando-o em seu outro complementar, Abreu condensa ao mesmo tempo tais narrativas sob o signo dúplice da origem e fim, materializando a idéia do eterno retorno e da permanente transformação. Observe-se agora como tal dominância de sentido refletir-se-á nas três primeiras narrativas deste bloco, todas elas versando sobre a busca do amor.

O primeiro conto, intitulado "A Maldição dos Saint-Marie", é na verdade um romance escrito pelo autor em 1962, quando tinha 12-13 anos, por ocasião de um concurso escolar. O conto traz como personagem principal a jovem Adriana, camponesa seduzida por um nobre chamado Fernando Saint-Marie. O cenário é composto por um castelo e bosques franceses, às voltas dos Pirineus. Ao contar ao nobre que está grávida, é insultada por Fernando, que a espanca e a abandona. Voltando ao castelo, encontra-se com Eleonora, prima distante e noiva de Fernando. Quando cai a noite, os três personagens têm seus pensamentos observados pelo narrador: Fernando está tenso, pensando na possibilidade de que Adriana conte à sua (dele) mãe que está grávida; Eleonora começa a desconfiar que seu noivo tem uma amante na vila, e dorme afogando lágrimas no travesseiro; finalmente, Adriana planeja sua vingança, se preparando para infiltrar-se no castelo como criada. Enquanto isso, Eleonora está em seu quarto, gritando apavorada, atormentada por fantasmas. Acudem-na Amália e Dona Ilsa, a matriarca Saint-Marie, e ambas comentam que Eleonora deve estar enlouquecendo.

Mais um dia começa, e a família Saint-Marie reúne-se para o café. Adriana começa a trabalhar no castelo. Durante o café, Ilsa anuncia que seu outro filho, George, voltará em breve a morar 
com a família, no castelo. A notícia desagrada Amália. Fernando, que havia ficado em seu escritório trabalhando sem descer para o café, nota que Adriana está no castelo, e fica preocupado, pensando que esta falará de sua gravidez para Dona Ilsa. Puxa-a então para o seu quarto e pergunta o que ela faz ali, ao que ela responde "[e]stou empregada aqui, Fernando, e aqui ficarei até meu filho nascer" (ABREU, 1995,p. 25).

À hora do almoço, ocorre o anunciado retorno de Georges ao castelo. Logo os olhos dele e os de Adriana cruzam-se: "George sorriu para Adriana, simpatizara com ela. A moça retribuiu-lhe o gesto, sorrindo timidamente. E ficariam ali a fitar-se se Ilsa não os interrompesse" (ABREU 1995, p. 26). Fernando tudo percebe e sente-se enciumado. À noite, Adriana serve o jantar a George em seus aposentos, e se descobre apaixonada: "Adriana sentia que encontrara o seu verdadeiro amor e estava feliz. Ela amava George como nunca tinha amado ninguém. Era um sentimento puro, calmo, belo, muito diferente da violenta paixão que sentira por Fernando" (ABREU, 1995, p. 27). No dia seguinte, George declara estar apaixonado por Adriana. O conflito estava posto.

Após o almoço, Dona Ilsa e Adriana saem para uma caminhada, e a matriarca diz: "[m]inha filha, sou velha e experiente, não procure esconder nada de mim. Eu sei o que há. Você... você vai ter um filho, não é isso?” (ABREU, 1995, p. 29). Entretanto, Ilsa se mostra piedosa e comunica a Adriana que não tem intenções de expulsá-la do castelo. Mais tarde, durante o jantar, Eleonora tem um mal-estar súbito, oportunidade para que o velho Danilo de SaintMarie (patriarca praticamente inválido, mas cujos conselhos eram sempre ouvidos) fale sobre a maldição que paira sobre a família: "[m]inha filha, ouça um conselho ditado por um homem velho e experiente. $\mathrm{O}$ que você tem sempre aconteceu com as noivas dos Saint-Marie, algumas chegam a morrer antes de casar e..." (ABREU, 1995, p. 31). Em seguida, revelando à Eleonora que esta é a maldição da família, sugere que se casem o mais rápido possível. Marca-se então o casamento entre Eleonora e Fernando para o próximo mês. Após o jantar, George e Adriana decidem comunicar seu noivado 
no dia do casamento de Fernando. Eleonora, por sua vez, continua tendo alucinações até o dia do casamento.

Chegando o dia da cerimônia, Adriana vai até o quarto de Eleonora para preparar a jovem para a celebração. Realiza-se então a cerimônia, e George anuncia seu noivado; todos se dirigem então para o castelo, no qual um grande almoço seria servido. Entretanto, logo em seguida, Eleonora se lança de um precipício, suicidando-se.

O clima fica então muito pesado sobre a família Saint-Marie nos dias seguintes, e logo Adriana começa a ter as mesmas visões de Eleonora. Apressam-se todos a realizar o casamento, desta vez praticamente em segredo. Cinco dias depois, durante a madrugada, ouviram-se gritos enlouquecidos vindos do quarto de Amália. Esta, enlouquecida, corria pelos corredores austeros do castelo com um toco de vela na mão, ateando fogo em tudo, enquanto gritava: "Eleonora morreu! E Adriana morrerá também! Os SaintMarie morrerão todos! Eu os matarei um a um! Sempre fui tratada como uma criada, mas me vingarei! Hei de matar a todos, todos!" (ABREU, 1995, p. 41).

Todos fogem do castelo em chamas, e Fernando, pouco antes de morrer, pede perdão à Adriana. Amália finalmente confessa seus crimes Finalmente, abandonando as ruínas do castelo os noivos caminham abraçados, "parecendo uma promessa de esperança e fé no futuro" (ABREU, 1995, p. 43). Dois traços dessa narrativa ficam muito evidentes pelo que foi visto até aqui. O primeiro deles diz respeito às histórias de contos de fadas enquanto uma espécie de matriz para o texto; o segundo diz respeito à técnica de releituraadaptação tão cara a Caio Fernando Abreu, que pode ser observada pela superposição da matriz fabular a questões contemporâneas do jovem contista, como as intrigas e os triângulos amorosos, o sexo antes do casamento e a vingança passional. $O$ fato de estar sob o signo de Ch'ien traduz também a importância dessa narrativa - vista pelo próprio autor como tosca e imatura - para o conjunto de sua obra. Sendo Ch'ien o primeiro hexagrama, o hexagrama da origem, esta narrativa primeira permite captar algumas preocupações que 
vão se repetir ao longo da obra do escritor: os contos de fada (retomados na segunda narrativa, intitulada "O Príncipe Sapo"), o sexo, a solidão e o abandono (leitmotiv do livro Morangos Mofados) e a preocupação com o místico e com o sobrenatural (a velha negra que aparece en passant no conto e que pode ser vista como prenúncio das influências da afro-religiosidade em narrativas como "Dodecaedro", incluída em Triangulo das Aguas). Sob o signo das mutações, tudo flui e evolui, e a "tosca narrativa" acaba dando origem a uma peça de teatro, tal como afirma Abreu no "conto do conto" deste texto.

$\mathrm{Na}$ segunda narrativa, intitulada "O Príncipe Sapo", o tema do amor e o mote das fábulas infantis é retomado. Entretanto, ao contrário de "A Maldição dos Saint-Marie", este conto não segue o típico script narrativo dos contos de fada; ele vai trazer a história de Teresa, uma mulher quase quarentona, solteira e ainda virgem. Teresa foi vendo a vida passar, esperando a chegada do grande amor e vendo suas irmãs casarem. Todas elas. Após a morte dos pais, Teresa herda a casa, recebe visitas das irmãs e começa a dedicar o tempo ocioso a ler histórias infantis, desenvolvendo então o curioso hábito de se pôr à janela para espiar a vizinhança (e procurar marido). Vai colocando apelidos nas pessoas, todos tirados de histórias infantis. Até que surge o príncipe sapo.

O príncipe sapo, que a princípio apenas desperta o humor de Teresa, começa a atormentá-la em seus sonhos, até que ela finalmente se encoraja e resolve procurá-lo, embora sem sucesso. Indagando por ele pela vizinhança, descobre que o príncipe sapo se chama Francisco: "[e]ra professor de piano, pobre solteiro, morava na pensão da esquina. O nome: Francisco, todos chamavam de Chico (ABREU 1995, p. 50; 51). Teresa decide comprar um piano, despertando a ira e a desaprovação de todas as irmãs e cunhados. Procura então Chico para começar suas lições de piano:

No começo tinha nojo dele. O Homenzinho apagado demais, humilde demais, sempre quieto, como 
consciente do desprezo que provocava, e por isso mesmo mais desprezível. Mas ao cair de uma tarde, Teresa surpreendeu-se a olhá-lo com pena, depois com compreensão, depois com simpatia, depois... Bem, noutro dia suas mãos tocaram-se rápidas sobre o teclado. Afastaram-se logo. A dele trêmula, nervosa; a dela hesitante; ambas, encabuladas. No dia seguinte buscaram-se discretamente, tocando-se como que por acaso, as quatro mãos. Uma semana mais tarde olharamse nos olhos. Olhos fatigados, de gente quase velha, quase sem ilusões (ABREU, 1995, p. 52).

Finalmente, Teresa toma coragem e pede Chico em casamento, ao que ele responde com uma negativa: "[f]oi no quartel, há muitos anos. Uma granada, você sabe, explosão, um acidente, estilhaços. Não sou um homem inteiro. Só meio homem, entende, Teresa? Não me obrigue a falar nisso!" (ABREU, 1995,p. 55). Chico então se retira lentamente, e nunca mais retorna. Quanto a Teresa, vendeu o piano e fez uma grande fogueira no quintal, onde jogou todos os livros infantis que com tanto afinco lera. E, com eles, queima também suas esperanças.

No terceiro conto, "A Visita", Abreu trabalha ainda com uma história de amor (ou a sua respectiva busca), mas desta vez sem lançar mão da "moldura" dada pelos esquemas narrativos dos contos de fadas, tal como nas duas narrativas vistas anteriormente. Ainda lançando mão do "conto do conto", Abreu adianta ao leitor desatento que "A Visita" traz inúmeras relações intertextuais com a literatura latino-americana, particularmente Fuentes e García Márquez.

Tudo começa quando um estranho homem chega devagar e senta-se à varanda de uma casa, um homem "de pés descalços, semelhante a raízes” (ABREU, 1995, p. 58). As crianças o evitavam a princípio, mas aos poucos ninguém mais dava atenção para aquela figura plantada na varanda. Aos poucos, entretanto, a presença daquele homem na varanda começa a perturbar a ordem natural das coisas: 
Mas com o dia avançando, as sombras ampliavam a presença do homem pela casa inteira. Essa sombra se infiltrando devagar em cada quarto jogava no rosto de cada um aquilo que não haviam sido, que não haviam feito, tudo aquilo que tinham apenas ameaçado ser, intensos e cheios de sangue, para depois se amoldarem num dia-a-dia feito de automatismos. Quieta, remota, a presença do homem era uma afronta (ABREU, 1995, p. 59).

Valentina, a matriarca da família, começa aos poucos a se mostrar mais perturbada por aquela presença do que as outras pessoas da família:

Valentina viu que seus pés descalços pareciam raízes grossas ameaçando entrar pelo chão de tijolos, viu que suas unhas eram longas, ovaladas e quase verdes, feito folhas, e que seu rosto pétreo parecia um fruto sendo aos poucos esculpido, ainda verde, mas cheio de sementes que transpareciam no olhar (ABREU, 1995, p. 61).

Assustada, Valentina retorna para casa, indo dormir. No dia seguinte, quando os filhos estavam no trabalho, os netos na escola e as noras ocupadas com os afazeres domésticos, subiu até o quarto de sua mãe, e afirma: "[e]le voltou”, ao que sua mãe responde: "[é] tempo" (ABREU, 1995, p. 62). A partir daí, Valentina começa a perceber e a reagir ao mundo de forma ímpar. Finalmente, ao final do conto, Valentina aproxima-se do homem-árvore e percebe que o fruto está maduro. Esmagando-o entre os dedos, leva seu sumo aos lábios "[e] quando finalmente sentiu-se protegida e úmida, e limpa e sorridente outra vez, e confortável e em paz, deixou que seus movimentos se espaçassem, suspirou e morreu" (ABREU, 1995, p. 66).

Cortando a narrativa, várias cenas do conto lembram o realismo mágico latino-americano. Valentina tecendo sua trama azul-marinho, as crianças comendo terra no quintal ou as orgias promovidas pelos filhos lembram muito certos episódios de Cem Anos de Solidão. Entretanto, o que chama a atenção é o amálgama 
entre o marido de Valentina (supostamente falecido) e a figueira no quintal. A relação travada entre Valentina e a figueira/marido, culminando com a compreensão e a súbita morte desencadea um desfecho epifânico, constante em várias narrativas de Abreu. Não é à toa que seu livro de crônicas se chama Pequenas Epifanias, e curiosamente publicado apenas depois de sua morte.

\section{EVIDENCIANDO O INTERTEXTO ORIENTAL}

Para entender a relação entre essas três narrativas e o intertexto chinês, cabe retomar as Linhas Mutáveis do I Ching. De acordo com o Tao, princípio subjacente ao oráculo, apenas a não-ação é capaz de permitir que a consciência visualiza claramente os problemas e suas possíveis soluções. Assim, as imagens contidas no I Ching funcionam de forma análoga às parábolas bíblicas, ilustrando princípios a partir dos quais se deve seguir para enfrentar obstáculos. As três narrativas aqui analisadas rondam todas em torno de uma mesma questão, a saber, a busca do amor. E, se forem analisadas à luz das máximas do I Ching, é possível observar que elas apontam para uma trajetória que parte de pequenas mutações e deslocamentos, abarcando as seis máximas das Linhas Mutáveis.

Comecemos pensando a primeira protagonista, Adriana. Seu percurso na narrativa começa com a gravidez e o abandono, e culmina com o encontro de seu grande amor. Ora, logo após o primeiro conflito com Fernando, Adriana porta-se de acordo com a primeira máxima ("O Dragão se esconde. Não é o momento de agir"). Ao invés de se deixar conduzir pela raiva contra Fernando, Adriana aguarda pela oportunidade de concretizar seus planos de vingança, o que acaba ocorrendo quando, mais tarde, adentra $\mathrm{o}$ castelo como criada. Após seus primeiros atritos com Fernando, Adriana comporta-se novamente como se estivesse ouvindo a segunda máxima do I Cbing ("O Dragão aparece em campo. É favorável encontrar pessoas"); ela não apenas encontra pessoas, firmando um pacto de amizade e cumplicidade com Dona Ilsa, como aceita George como seu novo amor. Fernando morre ao final da narrativa, 
não por obra nem graça de Adriana; ao contrário, ele redime-se, pedindo perdão a ela (que por sua vez aceita). Em síntese: Adriana transformou não apenas a si mesma, mas também ao ambiente que a cercava e teve a sua justiça feita. A justiça não é vista aqui como algo normativo ou punitivo, ela não tem esse caráter de valor; ao contrário, é vista como o resultado do re-ordenamento natural do universo a partir do momento em que alguém (no caso da narrativa, o príncipe Fernando) desestabiliza com suas ações o fluir natural dos acontecimentos.

Na segunda narrativa, o comportamento de Teresa mostrase condizente com a terceira máxima (" $O$ bomem está atento e ativo. Suas preocupacões o acompanbam até o anoitecer"). Ainda que aturdida pela espera de um marido, Teresa se mantém atenta, observando da janela possíveis candidatos para casar entre os passantes. Até que, finalmente, conhece Chico-Príncipe-Sapo. Ao propor-lhe casamento, vê-se frustrada, dado que Chico teve a genitália atingida por um estilhaço de granada enquanto estava no exército. É neste ponto que a quarta máxima se faz ouvir: "O Dragão, ainda escondido, prepara-se para sair". Para compreendê-la, entretanto, faz-se necessário observar o comentário do Duque de Chou incorporado às Linhas Mutáveis:

Embora se tenha atingido uma posição elevada, ainda é possível subir mais. É uma encruzilhada; há dois caminhos possíveis: renunciar à luta e isolar-se, para desenvolver a própria vida interior, ou continuar, para alcançar uma posição muito importante e influente. A escolha deve ser feita segundo a própria consciência (I CHING, 1989, p. 15).

É a partir deste comentário que pode ser entendida a atitude de Teresa: Teresa opta pela primeira opção, a de continuar sozinha e desenvolver a própria vida interior. Isso fica claro no momento em que a protagonista queima todos os livros infantis que lia e relia obsessivamente. Romper com as narrativas de "príncipes- 
encantados” não significa aceitar a frustração e interromper a busca; ainda que Teresa termine com um acesso piromaníaco, faz-se necessário lembrar que o fogo não funciona apenas como símbolo da intensidade/insanidade, mas também da iluminação espiritual. Logo, esse acesso piromaníaco de Teresa pode ser visto como a mesma loucura que se abateu sobre os apóstolos quando tomados pelas línguas de fogo do Espírito Santo, cena relatada nos Evangelhos das Sagradas Escrituras. Não é difícil aceitar que após atear fogo a seus livros infantis Teresa tenha desenvolvido uma forma outra de conduzir sua existência, e talvez o fato de encararmos seu fim como o de uma pessoa derrotada pelas convenções seja ilustrativo de nossa própria capacidade de não entender o entusiasmo de Teresa com seu novo caminho interior. Lembremos que o entusiasmo, a criatividade e o impulso inicial são conceitos que também estão sob o signo de Ch'ien na tradição oriental.

Finalmente, no terceiro conto (“A Visita”), a personagem Valentina, que não é apenas a protagonista, mas também a focalizadora ${ }^{3}$ da narrativa, parte da quinta máxima ("o Dragão está voando no alto do céu. É preciso encontrar pessoas importantes"), tanto que rapidamente ela apercebe-se que o homem sentado na varanda é seu marido. Entretanto, todo um processo de assimilação é necessário para que Valentina compreenda no todo a extensão de sua visão. Quando vislumbra o rosto do falecido marido no figo ainda verde, consulta a sabedoria da mãe para saber o que deve fazer. O hermético diálogo que mãe e filha estabelecem assemelha-se muito ao processo de consulta ao milenar oráculo chinês. Segundo especialistas no processo de utilização do I Ching como oráculo, suas respostas são muitas vezes tão herméticas que só fazem sentido quando o problema está solucionado. Ainda que pareça, desta maneira, que uma consulta a tal oráculo se revele inútil, de acordo com o pensamento oriental isso serve para indicar que as coisas caminham no ritmo certo, no mesmo fluxo que o restante dos acontecimentos do universo.

A mensagem lacônica da mãe de Valentina é tempo é análoga 
à sexta máxima: "o Dragão invade um território que não é seu, ultrapassando os limites”. O Dragão, que pode ser visto como a própria Valentina, ultrapassa seus limites ao invadir os limites do "marido-árvore". Ao ultrapassar os limites da vida, osculando o simbólico fruto que não é mais do que o próprio rosto de seu marido, Valentina morre. Entretanto, ela ultrapassa seus próprios limites, na medida em que se funde com o marido, aceitando uma existência que não é mais a da vida carnal, passando a habitar o mesmo mundo etéreo do marido, com o qual pode finalmente se reencontrar.

Assim, da busca plenamente realizada da primeira narrativa, Caio Fernando Abreu trata a busca afetiva como renúncia em favor da reflexão interior em "O Príncipe Sapo" para, finalmente,

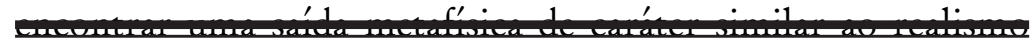
mágico latino-americano. Neste percurso, pontua sua trajetória com máximas implicitamente situadas, deixando para seus leitores o papel de refazer percursos a partir de pequenas pistas, como o hexagrama colocado no início de cada bloco de Ovelhas Negras. A partir do I Ching, foi possível reconstruir parte do percurso, extraindo sentidos e produzindo uma interpretação que leva em conta não apenas insigts, mas referências textualmente citadas pelo escritor, que abrem margem a um percurso singular de leitura, que conjuga a filosofia oriental como intertexto explícito da obra. Para finalizar, retomo uma frase do contista, pronunciada a respeito do suposto hermetismo de seus contos: "talvez seja um pouco cifrado, mas para um bom leitor certo mistério nunca impede a compreensão" (ABREU, 1995, p. 244).

\section{NOTAS}

${ }^{1 " C r e i o ~ q u e ~ o ~ m a i s ~ p e r i g o s o ~ n e s t e ~ I n v e n t a ́ r i o ~ e ́ ~ a ~ e x c e s s i v a ~ i n f l u e ̂ n c i a ~}$ de Clarice Lispector, muito nítida em histórias como Corujas ou Triângulo Amoroso: Variaçoes Sobre o Tema. Mas há ainda outras 
influências (...)" ABREU, C. F. Inventário do Ir-Remediável. 2. ed. Porto Alegre: Sulina, 1995. p. 6.

${ }^{2} \mathrm{Um}$ dos poucos trabalhos que conheço que se encaminha em direção a uma exploração da simbólica de Abreu é a dissertação de mestrado de Mairim Piva, intitulada Uma Figura às Avessas: Triângulo das Águas, de Caio Fernando Abreu, na qual a autora trabalha a partir da crítica do imaginário (calcada sobre o pensamento de Gilbert Durand e Gaston Bachelard) sobre a obra Triângulo das Águas.

${ }^{3}$ Mieke Bal desenvolve em seu Narratology: introduction to the theory of narrative (2nd ed. Toronto/Buffalo/London: University of Toronto Press, 1997) a noção de focalizador, que ela diferencia da de narrador,

partindo de algumas considerações já feitas por Gerard Genette. Segundo a autora, é possível identificar o focalizador de uma narrativa a partir dos verbos de percepsão utilizados por este (por exemplo, "fulano observava que beltrano estava pálido"); a partir desses verbos é que se torna possível observar de que ponto os eventos estão sendo narrados.

Afirma também a autora que as funções de focalizador podem ou não se acumular em uma mesma voz; assim, no caso do conto "A Visita", não há a coincidência entre o narrador (homodiegético intruso, pois ele pode "ver" o pensamento da protagonista) e a focalizadora (a personagem Valentina). A coincidência entre narrador e focalizador em uma mesma voz resulta naquilo que Genette chama de narrador autodiegético, combinação que não merece ser aqui explorada, visto que não ocorre em nenhuma das narrativas analisadas.

\section{REFERÊNCIAS}

ABREU, Caio Fernando. Triângulo das Águas. 2. ed. rev. pelo autor. São Paulo: Siciliano, 1991. 
. Ovelhas Negras. Porto Alegre: Sulina, 1995.

. Inventário do Ir-Remediável. 2. ed. Porto Alegre: Sulina, 1995.

AGUIAR E SILVA, Vítor Manuel de. Teoria da Literatura. v. 1. Coimbra: Almedina, 1993.

BAL, Mieke. Narratology: introduction to the theory of narrative. 2nd ed. Toronto/Buffalo/London: University of Toronto Press, 1997.

BRIK, O.; et all. Teoria da Literatura: Formalistas Russos. Tradução: Ana Maria Ribeiro, Maria Aparecida Pereira, Regina L. Zilberman e Antônio Carlos Hohlfeld. Revisão: Rebeca Peixoto da Silva. Org., Apresentação e Apêndice de Dionísio de Oliveira Toledo. Prefácio de Boris Schnaiderman. Porto Alegre: Globo, 1971.

DURAND, Gilbert. As Estruturas Antropológicas do Imaginário. São Paulo: Martins Fontes, 1996. 
209 